\title{
Pseudoepitheliomatous Hyperplasia
}

National Cancer Institute

\section{Source}

National Cancer Institute. Pseudoepitheliomatous Hyperplasia. NCI Thesaurus. Code C97115.

A benign lesion characterized by epidermal and adnexal epithelial hyperplasia. It is caused by chronic inflammation and infection. It may be associated with cutaneous neoplasms as well. 